\title{
ENRIQUE VILA-MATAS: EMBAIXADOR DA LITERATURA READY-MADE
}

Thais Kuperman Lancman*

(iD) https://orcid.org/0000-0002-0418-4690

Helena Bonito Couto Pereira**

(iD) https://orcid.org/0000-0002-1642-5447

Como citar este artigo: LANCMAN, T. K.; PEREIRA, H. B. C. Enrique Vila-Matas: embaixador da literatura ready-made. Todas as Letras - Revista de Lingua e Literatura, São Paulo, v. 22, n. 3, p. 1-13, set./dez. 2020. DOI 10.5935/1980-6914/eLETDO 2013711

Submissão: julho de 2020. Aceite: setembro de 2020.

Resumo: Este artigo busca discutir a produção literária de Enrique Vila-Matas à luz da trajetória pessoal e artística de Marcel Duchamp, bem como dos conceitos inseridos por ele na esfera artística, e determinantes no que entendemos atualmente por artes visuais. A partir de Duchamp, integrante do que Vila-Matas considera sua "Central Criativa", o autor catalão introduz práticas, reflexões e conceitos em suas obras, utilizando para isso diferentes procedimentos. Nesse sentido, destacamos o projeto literário inaugurado por Vila-Matas com História abreviada da literatura portátil e a noção de literatura ready-made, uma reflexão acerca da produção de autores contemporâneos com a qual o autor se identifica.

Palavras-chave: Literatura contemporânea. Artes visuais. Enrique Vila-Matas. Marcel Duchamp. Ready-made. 


\section{Um Duchamp gue pousou Na sopa de Vila-Matas}

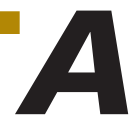

produção do escritor catalão Enrique Vila-Matas é marcada por uma ênfase progressiva em determinados temas e figuras. Embora seja possivel afirmar que se trata de um universo suficientemente amplo de forma a evitar que suas obras se tornem repetitivas, também é perceptivel que, dificilmente, temas e figuras de uma narrativa não ecoarão em outras produções do autor.

Entre as recorrências na obra de Vila-Matas, há o tema do fracasso, por exemplo, que surge como foco de estudo acadêmico, em Ares de Dylan, e como a busca fracassada por um gênio literário do editor Samuel Riba, em Dublinesca. O mundo da literatura, aliás, é presença constante, em obras como Dublinesca, Paris não tem fim, Bartleby \& companhia e O mal de Montano. Nesse aspecto, o autor não se restringe à figura do escritor e ao processo criativo, mas compreende que fazem parte da esfera literária o editor, o crítico, o livreiro e, claro, o leitor.

No mundo da literatura, como elaborado por Vila-Matas, também há muitas linhas dedicadas ao universo em constante expansão de suas referências literárias. Em primeiro lugar, seus protagonistas viajam. Deixam Barcelona em busca de Portugal, da Irlanda, da Alemanha, da Hungria. As viagens presentes nas narrativas são, elas mesmas, viagens rumo aos primórdios da literatura, a partir da referência à viagem original, a Odisseia, como o próprio autor diz. Trata-se, portanto, de uma conexão direta com a tradição, constantemente revisitada e reverenciada. Ademais, há a repetição constante de nomes, principalmente autores, mas também artistas plásticos e pensadores, que norteiam a produção de Vila-Matas por meio do diálogo e da intertextualidade, entre eles o pensador alemão Walter Benjamin e os escritores Robert Musil, Robert Walser, e Raymond Roussel. Também integram sua constelação de referências personalidades emblemáticas da vanguarda e do dadaísmo, como o poeta Tristan Tzara e o artista francês Marcel Duchamp. Entre os nomes contemporâneos de Vila-Matas que são recorrentes em suas narrativas, estão o escritor norte-americano Paul Auster e a artista Sophie Calle. Nota-se, portanto, que a escrita de Enrique Vila-Matas tem como inspiração outros autores, mas também artistas e pensadores que dialogam com a literatura e a ficção sem a produzirem de fato.

Duchamp é a figura central daquilo a que Joca Reiners Terron (2011) se refere como "o Big Bang na obra de Enrique Vila-Matas". Tal fenômeno, segundo Terron, é a novela História abreviada da literatura portátil, de 1985, que narra a história de uma curiosa sociedade secreta, os shandys, composta por artistas, escritores e intelectuais. Os princípios norteadores do grupo são o amor à escrita como diversão, a insolência, o espírito inovador.

Em relação à produção artística, a literatura portátil era o objetivo e o que unia os shandys. Por portátil, entendem-se obras leves, o que, em última instância, consistia na sarcástica rejeição a uma literatura canônica e sisuda, com L maiúsculo. Ademais, a sociedade secreta também encara a portabilidade de maneira literal, aspecto no qual Duchamp é uma referência importante:

A história da literatura portátil: uma história europeia nas suas origens e tão ligeira como a mala-escritório com a qual Paul Morand percorria em comboios de luxo a iluminada Europa noturna: escritório móvel que inspirou a Marcel Duchamp a sua boîte-en-valise, sem dúvida a tentativa mais genial de exaltar o 
portátil em arte. A caixa-mala de Duchamp, que continha reproduções em miniatura de todas as suas obras, não tardou em converter-se no anagrama da literatura portátil e no símbolo em que se reconheceram os primeiros shandys (VILA-MATAS, 1997, p. 11).

A caixa-mala (boîte-en-valise) não é apenas uma representação imagética dos shandys, mas também de toda uma literatura concebida e praticada por Enrique Vila-Matas que se sustenta principalmente nesta, mas ainda em outras criações de Marcel Duchamp, e também uma trajetória que tem o artista francês como referência de postura ante a vida, o que, como mostraremos, é indissociável de uma postura ante a própria força criativa. $\mathrm{O}$ foco desta análise centra-se, portanto, na aproximação à caixa-mala como força-motriz do Big Bang, ponto inicial a partir do qual o projeto literário de Vila-Matas se consolidou.

\section{INÚTIL}

Tendo a caixa-mala como eixo da aproximação à obra de Duchamp, levantamos alguns de seus principais aspectos: trata-se de um museu portátil de réplicas em miniatura e fac-símiles criados com técnicas sofisticadas de reprodução (GIRST, 2014, pos. 433) ${ }^{1}$. Duchamp escolhia cópias reduzidas de suas obras anteriores, elaborava as pequenas mostras, transportava-as e, eventualmente, presenteava pessoas próximas com caixas-mala. Nas diferentes versões da obra, desde as iniciais, feitas em couro, as obras apresentadas mudavam. Depois da morte de Duchamp, outras versões da caixa-mala foram produzidas e comercializadas, mantendo o grande número de variações em seu conteúdo (GIRST, 2014, pos. 438).

Em relação ao projeto literário de Enrique Vila-Matas, compreendemos que, ao falar em literatura portátil e comparar a escrita e a publicação de livros com a caixa-mala de Duchamp, o autor reflete acerca do seu oficio enquanto mecanismo de reprodução do mundo em versão compacta e facilmente transportável, ou seja, todo livro é uma espécie de caixa-mala. Pensando em Vila-Matas, que constantemente revisita temas e referências, transformando cada romance em uma releitura de obras anteriores, o autor se aproxima ainda mais da caixa-mala: da mesma forma que Duchamp, por meio das caixas, selecionava e reorganizava suas intervenções passadas, criando algo novo, Vila-Matas reconfigura sua constelação de referências e assuntos em novas obras.

Essa é a sintese da arte de Duchamp, em especial na caixa-mala, e parece ser o que Vila-Matas potencializa como proposta literária. "É como se, para Duchamp, o livro fosse uma miniaturização do mundo que o leitor habita" (VILA-MATAS, 1997, p. 81). O livro enquanto caixa-mala, a narrativa como forma de transportar um mundo, libertando esse mundo de seus aspectos práticos, "a miniaturização como dispositivo de fantasia" (VILA-MATAS, 1997, p. 81), tornando o mundo um mistério rocambolesco a ser decifrado, ou um labirinto de possibilidades lúdicas.

A ideia da caixa-mala, como adotada pelos shandys em História abreviada da literatura portátil, não se restringia a uma apropriação do conceito de portabi-

1 Em obras consultadas em edição digital e sem referência à paginação da edição física, indicamos a posição da citação com a abreviação "pos.". 
DOSSIE

lidade. Há um aprofundamento da questão da miniatura enquanto característica indispensável:

[...] miniaturizar é tornar portátil, é a forma ideal de possuir coisas para um vagabundo ou um exilado. Mas miniaturizar é também ocultar. Duchamp, por exemplo, também se sentiu sempre atraído pelo extremamente pequeno, quer dizer, por tudo o que exigisse ser decifrado: emblemas, manuscritos, anagramas. Para ele, miniaturizar significava também tornar inútil: o que está reduzido encontra-se de certo modo livre de significado. A sua pequenez é, ao mesmo tempo, um todo e um fragmento (VILA-MATAS, 1997, p. 13).

Dissecando as possibilidades de interpretação do conceito de miniatura, portanto, encontramos sentidos diversos. Primeiro, a já mencionada facilidade de transporte. Essa ideia ecoa nas obras de Enrique Vila-Matas, que constantemente contempla viagens de seus protagonistas, com ou sem destino certo, com ou sem data para voltar. Às vezes turismo, mas muitas vezes fuga.

Em A viagem vertical, por exemplo, romance em que o catalão Federico Mayol deixa Barcelona rumo a Portugal, há a seguinte passagem:

Sim, era como se ao sair de Barcelona tivesse embarcado numa inesperada viagem, capaz de levá-lo à linha do horizonte de uma sabedoria do afastamento, era como se a cultura estivesse entrando nele através da música de palavras e frases soltas, que se aproximavam vindas de paises remotos para marcar o compasso de uma desconhecida poesia (VILA-MATAS, 2004a, pos. 2524).

O valor da viagem, portanto, vai além da mudança de ares. Deixar a casa rumo a um lugar novo é também se iniciar em uma outra linguagem, deixar-se invadir por poesia. Raciocínio semelhante surge em Não há lugar para a lógica em Kassel, obra que parte da viagem do autor a Kassel, Alemanha, convidado a participar da Documenta, mostra de arte contemporânea realizada em 2012. Lá, reflete sobre o propósito de sua viagem, entoando uma espécie de mantra progressivo e circular, que se repete ao longo do livro. Sua conclusão conflui para a noção de que viajar provoca alterações na maneira como ele se expressa:

[...] eu viajava ao centro da própria vanguarda contemporânea, ia a Kassel, via Frankfurt, buscar, com certeza, o mistério do universo e iniciar-me na poesia de uma álgebra desconhecida, e também encontrar um relógio oblíquo e um restaurante chinês e, é claro, tratar de encontrar um lar no meu caminho (VILA-MATAS, 2015, p. 41).

De volta à História abreviada da literatura portátil, miniaturizar também é ocultar, apontam os shandys, ao passo que Duchamp, como consta, se interessava por jogos de decifrar, mensagens escondidas. Nesse sentido, entram as alteridades, identidades trocadas, por vezes parecendo chistes, como o Urinol, uma das obras mais famosas de Marcel Duchamp, assinada por um certo R. Mutt. Foi com a caixa-mala, aliás, que confirmaram se tratar de uma obra de Duchamp. De maneira análoga, foi a partir de História abreviada da literatura portátil que Vila-Matas passou a inserir artistas reais e fictícios em suas obras, causando um embaralhamento proposital de biografias verdadeiras e inventadas (TERRON, 2011, n.p.).

Um dos usos que Vila-Matas faz desse jogo de identidades escondidas e reveladas é a constantemente revisitada personagem Rita Malú: 
Nunca houve melhor imitadora de Sophie Calle do que Rita Malú. Rita gostava que a considerassem uma artista, embora não estivesse nem um pouco segura de ser uma. Fizera experimentos variados com a verdade, o que alguém havia batizado como romances de parede e que não passavam de modestas homenagens a sua admirada Sophie Calle, a "artista narrativa" por excelência, a artista que tinha apenas um ano de diferença dela (VILA-MATAS, 2013, pos. 2531).

Rita Malú, personagem de Vila-Matas, seria uma versão (uma miniatura?) do próprio Vila-Matas. Malú imita Sophie Calle, artista francesa conhecida por trabalhos como Cuide de você e Suite veneziana, da mesma maneira como Vila-Matas repete na literatura procedimentos aprendidos com Duchamp. A lógica complexa se reforça quando Malú até mesmo se apropria da ideia de caixa-mala para sua imitação de Calle:

Três dias depois, Rita já estava em Lisboa, uma parada obrigatória antes de dar o salto para os Açores. Em sua mala (uma espécie de boîte-en-valise no estilo de Marcel Duchamp) levava resumida, miniaturizada, a obra de Sophie Calle, bem como um livro de Simone Weil, uma escritora que mexia com ela desde que soubera que desprezava as artes da imaginação, pois the pareciam um truque para dissimular o imenso vazio de nossa mortalidade (VILA-MATAS, 2013, pos. 2626).

Não é por acaso, portanto, que Rita Malú seja mencionada no próprio História abreviada da literatura portátil, como uma mulher que teria feito uma travessia marítima com Man Ray (VILA-MATAS, 1997, p. 29). E o jogo de Rita Malú e Sophie Calle ganha corpo com a narrativa Porque ella no pidió, na qual Vila-Matas - ou um narrador em primeira pessoa que em muito se assemelha ao escritor - fala de seus encontros e desencontros com Calle, que se desdobram nas andanças de Rita Malú, imitadora da francesa, e nas trocas artísticas entre Sophie Calle e Paul Auster, escritor americano que a transformou em personagem em seu romance Leviatã. A pedido de Calle, Auster escreveu uma série de instruções para uma performance, que foram publicadas com o título How to improve life in New York City (because she asked). O "porque ela não pediu" do titulo de Vila-Matas, portanto, é sua infiltração no jogo dos dois, como um intruso:

Sophie Calle nunca telefonou a minha casa, isso pertence à minha imaginação, da mesma maneira como é inventada a história dos meus encontros e desencontros com ela. Suponho que imaginei esse telefonema e tudo o mais porque estava cansado da atonia da minha existência e ansiava poder contar sobre uma vida mais interessante em meu diário de notas rápidas. [...] minha história será a do escritor que se atreve a viver o que escrever, nesse caso aquilo que inventou acerca de suas relações com Sophie Calle, sua "artista narrativa" preferida (VILA-MATAS, 2016, pos. 620).

Voltando ao conceito de miniatura como implementado na caixa-mala, há em História abreviada da literatura portátil o pensamento de que aquilo que foi miniaturizado se torna inútil. Um carro em miniatura, por exemplo, não serve como meio de transporte. A literatura, mundo em miniatura, convertido em palavras, não é um espaço onde se pode viver. Porém, da mesma maneira que isso liberta aquilo que é miniaturizado, a partir da representação literária também se poderia almejar uma experiência de vida desprendida de um sentido exato, um 
propósito. Não à toa, os protagonistas de Vila-Matas agem dessa maneira, buscando se desprender da rigidez lógica, dos propósitos claros em suas ações. É o caso de Riba, em Dublinesca, que realiza o absurdo funeral da literatura em Dublin, ou o narrador de Não há lugar para a lógica em Kassel - título que vem bem a calhar na reflexão proposta neste artigo -, que passa a noite em uma instalação artística de Pierre Huygue, um terreno baldio inóspito.

\section{DuChaMP ENgUANTO BIOGRAFIA}

Duchamp é mencionado em praticamente todas as obras de Enrique Vila-Matas. Entre elas, destacamos Paris não tem fim e Não há lugar para a lógica em Kassel, obras que se aproximam em diversos pontos, como observa Rodenas (2014). Em Kassel, o narrador revive "as melhores lembranças do meu início como artista" (VILA-MATAS, 2015, p. 243) ao interagir com obras de arte de vanguarda. Vanguarda, para ele, remete a Duchamp.

Duchamp é uma espécie de modelo vanguardista para o narrador de Não há lugar para a lógica em Kassel, como se observa no trecho a seguir:

$E$, como desejava tudo isso, pensava que a maneira mais direta de me tornar um "vanguardista" seria adotar um ar parecido ao de Marcel Duchamp ou Man Ray naquelas fotos do restaurante: vestir, por exemplo, como tinha observado que Duchamp vestia, uma camisa branca diferente a cada noite, uma espécie de uniforme vanguardista (VILA-MATAS, 2015, p. 158).

Há certa ironia nessa visão de vanguarda, como uma futilidade, uma questão de aparências, com um teor crítico em relação à atmosfera da Documenta. Como se muitos artistas buscassem ser vistos como membro de uma vanguarda esvaziada de sentido. O narrador, por sua vez, reconhece a intelectualidade inerente ao vanguardismo de Duchamp:

Eu ia sentado naquela manhã na parte da frente do ônibus dando graças a Deus e a Duchamp pela existência das teorias na arte. Consciente, além do mais, de que, por mais que eu tivesse que pôr os pés no chão e passar à prática tantas vezes, a teoria sempre seria a minha grande paixão (VILA-MATAS, 2015, p. 154).

Ele observa o aroma "romântico e duchampiano" de Kassel, "um paraíso para os que amavam as conjecturas intelectuais, os discursos teóricos, a elegância de certas especulações" (VILA-MATAS, 2015, p. 92). Ao localizar a vanguarda geograficamente, em Kassel, então, ela se torna algo a ser desfrutada não apenas pelos próprios vanguardistas, mas por todos aqueles que valorizam suas qualidades. O narrador se coloca em um lugar intermediário, como admirador da vanguarda nas artes, e como escritor, que busca inserir essa maneira de produzir arte no fazer literário.

Em Paris não tem fim, Vila-Matas também discorre a respeito do retorno à iniciação artística, por meio da visitação aos lugares em que o narrador viveu quando jovem e iniciante na carreira literária. Duchamp, em Paris não tem fim, é mencionado como "o único mito artístico de minha juventude que ainda não foi totalmente demolido” (VILA-MATAS, 2008, p. 47). Há, então, o Duchamp símbolo e metonímia de vanguarda - como sintese de uma postura desafiadora, típica da juventude, de um frescor que Vila-Matas deseja restaurar, e o 
Duchamp biográfico, de cuja trajetória Vila-Matas retira diretrizes para sua própria prática artística.

A fusão entre arte e vida é tanto uma viagem às origens do próprio autor quanto a recuperação da fé na vanguarda (RODENAS, 2014). Em O mal de Montano, essa fusão é a solução Duchamp:

Isto é, dedicar-se a não fazer nada, que é o que fazem os artistas que já sabem tudo. Acaso seria dramático sair de Duchamp pela vida, declarando-se estranho a esses artistas que repetem ojá feito, e encarnar em si mesmo a sabedoria de quem está de volta ao mar e de volta de tudo e, portanto, é um fantasma feliz, cujos gestos cotidianos não são mais que a sucessão alegre, por exemplo, dos invisíveis livros que vai escrevendo não nos papéis e sim no ar livre de cada dia ou na superficie furtiva da vida (VILA-MATAS, 2005, p. 31).

Nesse romance, em que um crítico literário, pai de um escritor, converte progressivamente um diário em romance, há um embate entre arte e vida, o qual Duchamp supera por meio da fusão que transforma o cotidiano em criação. Uma vida duchampiana seria composta por ações que se tornam redundantes em relação à escrita, tornando-a desnecessária. Assim, escrever para repetir fórmulas, como que preso a uma escrita pré-formatada, não seria apenas inútil, mas também nocivo. Entretanto, "precisamente porque a literatura nos permite compreender a vida, ela nos deixa fora dela" (VILA-MATAS, 2005, p. 309); assim, novamente uma qualidade herdada de Duchamp - o apreço pelas conjeturas filosóficas, pela ginástica mental - se faz presente como parceira da literatura.

A criação artística como alternativa à vida vivida, ou, ainda, a escolha pela vida, relacionada a Marcel Duchamp se repete em Bartleby \& companhia, em que Vila-Matas faz um inventário de escritores que, como o personagem da novela de Herman Melville, foram da ação para a inação, deixando de escrever. Vila-Matas inclui Duchamp nessa lista (mesmo ele não sendo rigorosamente um escritor):

Duchamp tampouco tinha muitas ideias. Um dia, em Paris, o artista Naum Gabo perguntou-lhe diretamente por que havia deixado de pintar: "O que você queria que eu fizesse?", respondeu Duchamp abrindo os braços. "Acabaram-se as minhas ideias." [...] Sempre quis colocar a arte a serviço da mente e foi precisamente esse desejo - animado por seu particular uso da linguagem, do acaso, da ótica, dos filmes e, sobretudo, por seus célebres ready-mades - o que socavou sigilosamente quinhentos anos de arte ocidental até transformá-la por completo. Duchamp abandonara a pintura havia mais de cinquenta (VILA-MATAS, 2004b, pos. 734).

Em Bartleby \& companhia, Vila-Matas defende, então, uma prática artística que completa a vida, dando significado a ela. Mais do que isso, ao adotar essa postura, os artistas que vivem dessa forma retornam à arte, revolucionando-a. Por esse motivo, viver e fazer arte como uma coisa só é o que permite, em última instância, que exista uma vanguarda, mesmo que seja uma vanguarda como os autores mencionados em Bartleby \& companhia, que escrevem pouco ou, misteriosamente, abandonam a escrita.

A arte de Duchamp nada tem a ver com ideias em profusão - ou seja, é uma arte radicalmente não original -, emergindo de um uso particular das poucas ideias, dos jogos mentais que surgem ao retorcer um repertório restrito. Este é 
um dos eixos duchampianos da literatura que Vila-Matas propõe, e que se mostra na repetição constante de temas e personalidades, por exemplo, a própria digressão que opõe a literatura e a vida.

A relação entre a vanguarda duchampiana, aquela de ideias rarefeitas, porém férteis, e aquela observada em Kassel é notada no elogio que o narrador faz à This variation, obra de Tino Sehgal exibida na Documenta. Essa obra, um salão escuro em que performers interagiam de maneiras inesperadas com os visitantes, foi uma das intervenções de destaque na mostra artística realizada em Kassel, em 2012. Sehgal, além disso, é um dos artistas mais relevantes na contemporaneidade. Na primeira visita do narrador à obra, ele aponta que:

Sehgal era um ilustre herdeiro de Duchamp. Porém, inovava? Poderíamos dizer que pertencia a alguma vanguarda? Não, não inovava. Mas, desde quando era necessário que a arte se dedicasse à inovação? (VILA-MATAS, 2015, p. 51).

Parte do que impressiona o narrador ao visitar a obra de Sehgal é seu caráter não inovador, e ainda assim (ou ainda, justamente por isso) vanguardista. Isso é o que o torna tão próximo de This variation, a ponto de ficcionalizar suas visitas. Destacamos a relação triangular estabelecida entre Sehgal, narrador e Duchamp, sendo este último o articulador, por meio da não inovação vanguardista. E essa proposta se intensificaria na Documenta, justificando que seja o centro da vanguarda. Em determinado momento, o narrador de Não há lugar para a lógica em Kassel assiste a uma entrevista com Chus Martínez, uma das organizadoras da mostra. Nela, ela diria:

Na arte não se inova, isso acontece em uma indústria. A arte não é criativa nem inovadora. Deixemos isso para o mundo dos sapatos, dos carros, da aeronáuti$c a$, é um vocabulário industrial. A arte faz, então você se vira como pode (VILA-MATAS, 2015, p. 52).

Em diversos momentos, observaremos esse narrador-autor se virando como pode.

\section{Arguivo vivo}

A própria maneira como Enrique Vila-Matas estrutura suas narrativas, a exemplo de Bartleby e companhia, dialoga com a arte de Marcel Duchamp. Em vez da aparente livre criação de uma narrativa, o autor catalão adota práticas de inventariar escritores e biografias, ou, ainda, de reportar e catalogar uma mostra de artes, como faz em Não há lugar para a lógica em Kassel. De forma análoga, Duchamp insere práticas de outros agentes da esfera artística em seus processos:

Ele substituiu os processos criativos e generativos tradicionalmente associados ao artista por uma infinidade de atividades aparentemente práticas - administrar, arquivar, curar, lidar, historicizar, divulgar, reproduzir etc. - que se tornaram legítimos procedimentos artísticos (FILIPOVIC, 2013, p. 295).

Nesse aspecto comunicativo da trajetória duchampiana, observamos também que suas práticas artísticas incluíram muitas atividades que hoje são vistas no escopo do trabalho do curador. Em uma conversa entre os curadores Hans Ulrich Obrist e Anne D'Harnoncourt, eles discutem a respeito de práticas cura- 
toriais iniciadas e incentivadas por Marcel Duchamp (OBRIST, 2010, p. 225). Obrist (2010, p. 222) destaca o uso dos arquivos:

Não o arquivo empoeirado, mas o arquivo como ímpeto para produzir conhecimento. Particularmente em relação a Duchamp, isso parece ser uma questão sobre a visão do museu, que é interessante porque você não tem apenas uma capela, por assim dizer, de Duchamp, mas tem também o arquivo. Acho que os arquivos são muito importantes; eles são fascinantes.

A questão do arquivo surge na obra de Vila-Matas na medida em que, como demonstramos, ele constantemente revisita e reorganiza seus conteúdos, e da combinação, somada a elementos alcançados em outras fontes, como as biografias de outros e citações de obras literárias de diferentes épocas, que consolida suas narrativas.

Assim podem-se analisar as biografias de personalidades das artes e da literatura, ou ainda, fatos, menções a quadros e referências histórias como o acesso ao arquivo pessoal do autor. O processo de constantemente revisitar um arquivo pessoal, composto por citações de outros como se fossem documentos arquivados, não é exclusivo de Vila-Matas, porém a maneira como ele o faz e exibe as engrenagens enquanto faz uso delas, além da menção constante ao artista francês, reforçam a leitura desses elementos enquanto uma literatura duchampiana, na medida que o arquivo vivo também é manipulado de maneira a criar quebra-cabeças literários.

\section{RADICALMENTE NÃO ORIGINAL}

Mencionamos algumas vezes como as repetições, às vezes com alterações sutis, são fulcrais na obra de Vila-Matas. Da mesma forma, o autor revisita constantemente sua Central Criativa, como costuma chamar a série de autores e artistas que o inspiram. Também falamos em uma proposta de ser "radicalmente não original"; a expressão é uma referência ao próprio autor:

Achei conveniente lembrar que o artista de hoje deve ser radicalmente não original. Exemplifiquei com John Cage, que compunha com 15 rádios no palco, sintonizando-os em tempo real. Sem dúvida ele também pensava que, para se criar algo novo, o artista tinha de encontrar um território onde pudesse ser radicalmente não original (VILA-MATAS, 2018, n.p.).

Radicalmente não original também foi o título de uma conferência proferida por Enrique Vila-Matas e pela artista Dominique Gonzalez-Foerster, em 2017. Nela, o autor se apresentou como Bastian Schneider, um colecionador e modificador de citações. "Ajudante intertextual" de escritores, Schneider questiona a autenticidade, "um fetiche reacionário" que produz apenas má literatura, e afirma: "querer ser original é uma ilusão" (VILA-MATAS; GONZALEZ-FOERSTER, 2017).

O que Vila-Matas afirma em sua conferência é que o caminho para a ficção é o da reescrita de tudo aquilo que o antecedeu. A originalidade e o estilo emergem da maneira como o escritor combina esse universo de citações e como as modifica.

É possivel observar, nas obras de Enrique Vila-Matas, de que modo essa proposta de não originalidade é executada e em que medida dialoga com Duchamp. As citações, biografias, e as próprias ideias e personagens que Vila-Matas resgata de romances anteriores são como os ready-mades de Duchamp, o urinol retirado 
de seu local original, assinado como obra artística e que, ao ser colocado nesse novo contexto, adquire significados e o potencial de uma obra de arte verdadeiramente original para sua época.

A inserção do ready-made no universo das artes, além de expandir a possibilidade de materiais ao infinito, a partir da livre apropriação, reforça a autoridade discursiva do artista (CRIMP, 2015, p. 195), por ser o indivíduo que, acompanhado do museu de arte, afirma que aquele objeto é uma de suas obras. O ready-made fala mais a respeito do funcionamento da arte do que sobre o próprio objeto, porém ele faz isso a partir do distanciamento estético imposto a candidatos improváveis à fruição estética. Assim, é Duchamp quem traz o enfoque comunicativo para as artes, que se tornaria a tônica dominante da arte contemporânea aplicável à literatura na medida em que

A língua é algo que já está aí, um ready-made, pronto para o emprego. Os usuários da língua não a inventam; eles a transformam ou mudam de lugar seus elementos (CAUQUELIN, 2005, p. 102).

Vila-Matas é um defensor da adaptação do ready-made na literatura:

O ready-made não é ruim para a literatura, desde que bem utilizado. Ou seja, sempre que permita ao escritor ter vínculo mais dinâmico com a literatura do que costumam ter a maioria dos "literatos" (VILA-MATAS, 2018, n.p.).

A não originalidade enquanto método, portanto, é defendida por Vila-Matas não como muleta para obras descartáveis, mas dentro das incontáveis possibilidades de combinações. Além disso, uma vez que exemplificamos o uso de procedimentos duchampianos pelo autor em obras que falam do universo literário, seja com personagens escritores, críticos, editores ou ainda fazendo referência a obras de outras épocas e nacionalidades, é notável o esforço do autor em justamente utilizar a ideia de reescrita permanente, muitas vezes irônica, como o lugar da reflexão acerca do meio literário como um todo, discordando do discurso que enaltece uma autenticidade inexistente. E, como Vila-Matas defende a figura do escritor, comparando-o ao toureiro, em sua capacidade de criar um estilo próprio dentro de uma arte consagrada (VILA-MATAS; GONZALEZ-FOERSTER, 2017), a não originalidade é um discurso de sinceridade e, por isso, possibilidade de exercer uma literatura verdadeira, pulsante e transmutável em vida. Prática e defesa da não originalidade se fundem, concretizadas no estilo do autor:

Melville, em The Confidence Man, transmite clara admiração pelo ser humano que pode metamorfosear-se em múltiplas identidades. O estrangeiro no barco fluvial de Melville executa uma brincadeira maravilhosamente duchampiana sobre si mesmo (Duchamp era brincalhão e amante da pura fantasia verbal, entre outras coisas, justamente por não acreditar muito nas palavras, adorava, acima de tudo, Jarry, o fundador da Patafisica, e o grande Raymond Roussel), uma brincadeira que usa os passageiros e o leitor ao colar "um cartaz junto ao escritório do capitão oferecendo uma recompensa pela captura de um misterioso impostor, supostamente recém-chegado do Leste; um gênio original em sua vocação, poderíamos dizer, embora não estivesse claro em que consistia sua originalidade" (VILA-MATAS, 2004b, pos. 754).

O trecho citado ilustra uma série de procedimentos adotados em diversas obras de Vila-Matas, e de que maneira eles se relacionam. Melville, autor, entre 
outras obras, de Bartleby, o escrivão, é um personagem. Não se sabe se o episódio da vida de Melville a que Vila-Matas se refere é real ou inventado, porém o Melville personagem, como o escritor catalão, se inspira em Duchamp. O texto, então, refere-se aos dois, unindo-os a outros dois membros da Central Criativa: Alfred Jarry e Raymond Roussel. Vila-Matas insere ainda uma citação de uma obra de Melville, em um processo que podemos associar a uma colagem, o uso do arquivo pessoal do escritor ou, ainda, o deslocamento semelhante a um ready-made. Por fim, o próprio assunto da citação remete ao procedimento. O tema em pauta é o conceito de gênio, questionando se o genial tem alguma relação com a originalidade, e sabemos que Vila-Matas rejeita essa ideia.

\section{LITERATURA READY-MADE}

Enrique Vila-Matas endossa o termo adotado por Shaj Mathew (2015), romance ready-made, para se referir a um grupo de autores contemporâneos que o inclui:

Assim como Marcel Duchamp questionou se um urinol poderia ser arte, o romance ready-made pergunta o que a literatura pode ser, e o que será no futuro. Em vez de tentar compreender a realidade por meio de detalhes concretos, onisciência, múltiplos pontos de vista ou qualquer outra coisa que se espere da ficção, o romance ready-made apresenta ideias ou levanta perguntas. Ele está mais interessado no conceito por trás de uma obra de arte - dele mesmo - do que em sua execução.

De fato, Vila-Matas abandona essas ferramentas, oriundas de uma proposta de ficção do século XIX, em detrimento de certo conceitualismo (MATHEW, 2015). Ao jogar com as convenções literárias, ele acaba movimentando o mesmo mecanismo que serve de tema para seus romances: o universo literário e seus atores. Ou, então, ele pode tecer comentários sobre a chuva em Barcelona, viagens entre países europeus, buscas fadadas ao fracasso, e o mais importante serão os procedimentos adotados para chegar ao texto, da mesma forma que Duchamp ora revela, ora esconde seu processo de escolha de objetos e da maneira de expô-los quando concebeu seus ready-mades.

As biografias, verdadeiras e falsas, a inserção de gêneros como o diário, a conferência e até as notas de rodapé são a essência da literatura ready-made, da não originalidade radical proposta por Vila-Matas. Aos moldes das artes visuais que, a partir de Duchamp, passaram a incitar o espectador a tornar-se ativo diante das obras, também o leitor de Vila-Matas é chamado a ter uma postura diferente no processo de leitura (MATHEW, 2015). O leitor se vira como pode, deixando-se levar entre personalidades que existiram ou não, cenas absurdas, embora por vezes reais, diante de momentos prosaicos totalmente fictícios, abandonando, em última instância, o pacto firmado desde a consagração do romance na tradição literária que formou Vila-Matas, seus conterrâneos e contemporâneos.

Há, portanto, duas dimensões da literatura ready-made exercida por Enrique Vila-Matas. A primeira é o questionamento das próprias práticas literárias e sua renovação por meio da apropriação de procedimentos originários em Duchamp. A ideia de não originalidade é encarada de tal maneira que ele não esconde essa referência, pelo contrário, seu aspecto inovador se dá pela transparência da constituição de sua Central Criativa. Notamos que a consolidação dessas práticas 
e a constante revisitação de Vila-Matas em temas, personagens e formas são ferramentas adaptadas de diversas criações de Marcel Duchamp, como a arte ready-made, o uso de arquivos, a constituição da caixa-mala.

A segunda dimensão da literatura ready-made diz respeito ao que Enrique Vila-Matas pontua, ao longo de suas obras - que uma postura diante da arte se reflete em uma postura diante da vida. Pois, se os objetos do cotidiano se fundem às obras de arte, também a criação artística pode se converter em uma maneira diferente de se viver. Assim, ser artista e de vanguarda não implica fazer arte, e sim inserir no dia a dia a produção sem sentido, as caminhadas sem rumo, a predisposição ao absurdo. E o verdadeiro artista poderia até mesmo abandonar aquilo que o consagrou para apenas viver. Não é por acaso que, ao combater o autêntico, Vila-Matas, quando personifica Bastian Schneider, também rejeita o normal (VILA-MATAS; GONZALEZ-FOERSTER, 2017). Sem a busca pela autenticidade, também se abandona a busca pela normalidade. A força transformadora que é, para Vila-Matas, a verdadeira criatividade, também é o desprendimento da uniformidade rasa e o que pode dar a voz única a um escritor.

\section{ENRIgUe Vila-Matas: AMbassador OF READY-MADE LITERATURE}

Abstract: This article aims to discuss the literary production of Enrique Vila-Matas under Marcel Duchamp's personal and artistic path, as well as the concepts introduced by him in the artistic sphere, and decisive in what we nowadays understand as visual arts. Based on Duchamp, member of what Vila-Matas considers his "Creative Center", the Catalan author introduces practices, reflections and concepts in his works adopting for this different procedures. In this sense, we highlight the notion of ready-made literature, a reflection on the production of contemporary authors with which Vila-Matas identifies.

Keywords: Contemporary literature. Visual arts. Enrique Vila-Matas. Marcel Duchamp. Ready-made.

\section{REFERÊNCIAS}

CAUQUELIN, A. Arte contemporânea: uma introdução. Tradução Rejane Janowitzer. São Paulo: Martins, 2005.

CRIMP, D. Sobre as ruínas do museu. Tradução Fernando Santos. 2. ed. São Paulo: Martins Fontes, 2015.

FILIPOVIC, E. The apparently marginal activities of Marcel Duchamp. 2013. Tese (Doutorado em História da Arte) - Departamento de Arte e Arqueologia, Princeton University, Princeton, NJ, 2013.

GIRST, T. The Duchamp dictionary. London; New York: Thames \& Hudson, 2014. MATHEW, S. Welcome to Literature's Duchamp Moment. The New Republic, 19 maio 2015. Disponivel em: https://newrepublic.com/article/121603/avantgarde-literature-starting-resemble-conceptual-art. Acesso em: 10 jun. 2020.

OBRIST, H. U. Uma breve história da curadoria. Tradução Ana Resende. São Paulo: BEI, 2010. 
RODENAS, D. La vanguandia y el espejo. El Periodico, Barcelona, 19 fev. 2014. Disponivel em: https://www.elperiodico.com/es/ocio-y-cultura/20140218/lavanguardia-y-el-espejo-3116071. Acesso em: 10 jun. 2020.

TERRON, J. R. O Big Bang portátil de Enrique Vila-Matas. 3 mar. 2011. Disponivel em: http://www.enriquevilamatas.com/escritores/escrreinerstj1.html. Acesso em: 2 jun. 2020.

VILA-MATAS, E. A viagem vertical. Tradução Laura Janina Hosiasson. São Paulo: Cosac \& Naify, 2004a.

VILA-MATAS, E. Bartleby \& companhia. Tradução Josely Vianna Baptista. São Paulo: Cosac \& Naify, 2004b.

VILA-MATAS, E. Exploradores do abismo. Tradução Josely Vianna Baptista. São Paulo: Cosac \& Naify, 2013.

VILA-MATAS, E. História abreviada da literatura portátil. Tradução José A. Baptista. Lisboa: Assírio \& Alvim, 1997.

VILA-MATAS, E. Não há lugar para a lógica em Kassel. Tradução Antônio Xerxenesky. São Paulo: Cosac \& Naify, 2015.

VILA-MATAS, E. O artista deve ser não original, diz Enrique Vila-Matas. [s.l.: s.n.], 2018.

VILA-MATAS, E. O mal de Montano. Tradução Celso Mauro Paciornik. São Paulo: Cosac \& Naify, 2005.

VILA-MATAS, E. Paris não tem fim. Tradução Joca Reiners Terron. São Paulo: Cosac \& Naify, 2008.

VILA-MATAS, E. Porque ella no lo pidió. 1. ed. Barcelona: Lumen: Penguin Random House Grupo Editorial, 2016. (Lumen Narrativa).

VILA-MATAS, E.; GONZALEZ-FOERSTER, D. LEFFEST'17 Bastian Schneider [Radicalmente não original]. Lisboa: [s.n.], 2017. Disponivel em: https://www. youtube.com/watch?v=iytHnp7R_Fk. Acesso em: 10 jun. 2020. 